\title{
Prediction of incidence and bio-psycho-socio-cultural risk factors of post-partum depression immediately after birth in an Iranian population
}

\author{
Fatemeh Abdollahi ${ }^{1}$, Mehran Zarghami ${ }^{2}$, Shariff-Ghazali Sazlina ${ }^{3}$, Azhar Md Zain ${ }^{4}$, \\ Asghari Jafarabadi Mohammad ${ }^{5}$, Munn-Sann Lye ${ }^{6}$
}

\begin{abstract}
${ }^{1}$ Department of Public Health, Psychiatry and Behavioral Sciences Research Center, Mazandaran University of Medical Sciences, Sari, Iran

${ }^{2}$ Department of Psychiatry, Psychiatry and Behavioral Sciences Research Center, Addiction Institute, Mazandaran University of Medical Sciences, Sari, Iran ${ }^{3}$ Department of Family Medicine, Faculty of Medicine and Health Sciences, Universiti Putra Malaysia, Serdang, Malaysia

${ }^{4}$ Department of Psychiatry, Faculty of Medicine and Health Sciences, Universiti Putra Malaysia, Serdang, Malaysia

${ }^{5}$ Injury Epidemiology and Prevention Research Center, Department of Statistics and Epidemiology, Faculty of Health, Tabriz University of Medical Sciences, Tabriz, Iran ${ }^{6}$ Department of Community Health, Faculty of Medicine and Health Sciences, Universiti Putra Malaysia, Serdang, Malaysia
\end{abstract}

Submitted: 27 November 2012

Accepted: 25 February 2013

Arch Med Sci 2016; 12, 5: 1043-1051

DOI: 10.5114 /aoms.2016.58642

Copyright (C) 2016 Termedia \& Banach

\section{Abstract}

Introduction: Post-partum depression (PPD) is the most prevalent mental problem associated with childbirth. The purpose of the present study was to determine the incidence of early PPD and possible relevant risk factors among women attending primary health centers in Mazandaran province, Iran for the first time.

Material and methods: A longitudinal cohort study was conducted among 2279 eligible women during weeks 32-42 of pregnancy to determine bio-psycho-socio-cultural risk factors of depression at 2 weeks post-partum using the Iranian version of the Edinburgh Postnatal Depression Scale (EPDS). Univariate and hierarchical multiple logistic regression models were used for data analysis.

Results: Among 1,739 mothers whose EPDS scores were $\leq 12$ during weeks 32-42 of gestation and at the follow-up study, the cumulative incidence rate of depression was $6.9 \%(120 / 1,739)$ at 2 weeks post-partum. In the multivariate model the factor that predicted depression symptomatology at 2 weeks post-partum was having psychiatric distress in pregnancy based on the General Health Questionnaire (GHQ) $(\mathrm{OR}=1.06,(95 \% \mathrm{Cl}: 1.04-1.09), p=0.001)$. The risk of PPD also lower in those with sufficient parenting skills $(O R=$ $0.78(95 \% \mathrm{Cl}: 0.69-0.88), p=0.001)$, increased marital satisfaction $(\mathrm{OR}=0.94$ (95\% Cl: 0.9-0.99), $p=0.03$ ), increased frequency of practicing rituals (OR $=0.94(95 \% \mathrm{Cl}: 0.89-0.99), p=0.004)$ and in those whose husbands had better education ( $\mathrm{OR}=0.03$ (95\% Cl: 0.88-0.99), $p=0.04$ ).

Conclusions: The findings indicated that a combination of demographic, sociological, psychological and cultural risk factors can make mothers vulnerable to PPD.

Key words: incidence, depression, post-partum.

\section{Corresponding author:}

Munn-Sann Lye

Department

of Community Health

Faculty of Medicine

and Health Sciences Universiti Putra Malaysia

PO Box 43400

Serdang, Malaysia

Phone: +989378351910

E-mail: Lyems9@yahoo.com,

mehrdadtaghipour@gmail.com 


\section{Introduction}

The post-partum period is recognized as a period when many mothers are vulnerable to a variety of emotional symptoms. The most prevalent mental or emotional problem associated with childbirth is post-partum depression (PPD), starting within four weeks after childbirth [1]. Researchers have frequently mentioned the importance of maternal mood within 2 weeks after delivery as a predictor of PPD [2].

According to Beck [2], PPD influences nearly $15 \%$ of all women in Western countries. However, later studies in developing countries showed ranges of $3.5 \%$ to $63.3 \%$ of PPD [3]. Cross-sectional studies have shown varying prevalence rates for PPD, ranging from $22 \%$ to $35 \%$ in various Iranian populations [4-7]; however, no researchers have ever documented risk factors of PPD in an incidence study in Iran.

Post-partum depression can produce adverse symptoms that can make motherhood one of the most tumultuous events in a woman's life [8]. Also, the mothers' social and personal adaptation skills are impaired, and the mother-child and marital relationships may be disturbed and affected by this disorder $[9,10]$.

A number of risk factors have been proposed for the development of PPD. However, these risk factors are not considered to be conclusive [11]. The extent to which factors predict PPD varies extensively in different studies, and recent evidence indicates that many of them are culturally determined and most of them present during pregnancy or immediately after birth.

The determination of the risk factors at pregnancy and early postpartum would aid the diagnosis of postpartum depressed mothers and prevent further adverse consequences. Thus, using the Edinburgh Postnatal Depression Scale (EPDS), this study was conducted to identify bio-psycho-socio-cultural risk factors in a cohort of Iranian women at greater risk for developing PPD immediately after childbirth for the first time in Iran.

\section{Material and methods}

\section{Procedures}

This investigation was designed as a cohort follow-up study to investigate demographic, social, cultural, psychological, obstetrics and gynecological and hormone-related risk factors in the development of PPD. All pregnant women with gestational age 32-42 weeks pregnancy who attended urban and rural primary health centers (PHCS) of Mazandaran University of Medical Sciences in northern Iran for prenatal care from January to June 2009 and fulfilled the inclusion criteria were invited to take part in this study to determine the incidence and probable risk factors of PPD at 2 weeks after birth. Mothers who were on pharmacological treatment for psychiatric problems as well as illiterate mothers were excluded from the study. Upon their agreeing to take part, written consent was obtained. Also all women who were depressed during weeks 32-42 of pregnancy according to the EPDS were excluded from the study, thus allowing new cases of PPD to be recognized. The study was approved by the Medical Ethics Committees of University Putra Malaysia and Mazandaran University of Medical Sciences in Iran.

\section{Assessment}

The recruitment of subjects for the study was done during weeks 32-42 of pregnancy and subsequently assessed at the second week after delivery. At the baseline, socio-demographic data and information on medical (especially obstetrical) factors, mental health, hormone-related conditions, abuse and also rituals and customs after childbirth was collected using a standard questionnaire that was developed by one of us (Fatemeh Abdollahi) after a comprehensive review of the literature on risk factors related to development of PPD. We also used the Premenstrual Syndrome Questionnaire (PMSQ) [12], the Social Support Appraisals Scale (SSA) [13], the Network Orientation Scale (NOS) [14], the General Health Questionnaire (GHQ-28) [15], the Marital Inventory (ENRICH) [16], the Life Events Rating Scale (LERS) [17] and the Parental Expectation Survey (PES) [18] to evaluate irritable mood before menstruation, availability of support, health status during pregnancy, marital relationship satisfaction, life events during the past 6 months and parenting self-efficacy respectively. Face and content validity of this questionnaire was examined by 10 experts in the Psychiatry and Behavioral Sciences Research Center of Mazandaran University of Medical Sciences, who examined each item for congruence in concept. Examining a sample of 60 healthy unselected pregnant mothers in PHCs, reliability of the questionnaire was calculated with Cronbach's $\alpha$ between 0.42 and 0.92 .

\section{Edinburgh Postnatal Depression Scale (EPDS) [19]}

Edinburgh Postnatal Depression Scale is a 10item self-reporting screening tool to evaluate mothers for postnatal depression [19] and can be completed by them in less than $5 \mathrm{~min}$. Each item is scored from 0 to 3 ("no, not at all" to "yes, quite often") according to the severity of symptoms during the past week [20]. Sensitivity and specificity of the Persian version of the EPDS were reported as $95 \%$ and $93 \%$ respectively in Shiraz-Iran [7]. 


\section{Variables under study}

In this study the dependent variable was PPD as measured by the Edinburgh Postnatal Depression Scale (EPDS). Scores of greater than 12 are indicative of probable PPD in an Iranian sample as reported by Namazi [7]. The independent variables included in the analysis addressed bio-psycho-socio-demographic factors as shown in Table I.

\section{Statistical analysis}

For better understanding of the predictors of PPD at two weeks after birth the relationship between probability risk factors and PPD based on the EPDS after excluding depressed mothers at weeks 32-42 of pregnancy was analyzed. Sequential logistic regression was used to determine the predication of membership in each of two categories: depressed (EPDS $\leq 12$ ) or non-depressed mothers (EPDS > 12). For determination of potential predictors of depression at 2 weeks postpartum, univariate analysis was performed. Subsequent to this, the variables that were statistically significant in the univariate regression analysis were tested in a hierarchical multiple logistic regression model. The odds ratios (OR) with their confidence intervals $(\mathrm{Cl})$ of $95 \%$ are presented. All tests with $p$-values of less than 0.05 were considered statistically significant. All analyses were performed using SPSS 20 (SPSS Inc., Chicago, IL, USA).

\section{Results}

\section{Response rate}

Of 2279 (96.6\%) women who completed the antenatal EPDS, 62 (3.44\%) mothers did not continue the study and 478 (21\%) who scored more than the threshold EPDS of greater than 12 were excluded from the analysis prior to delivery. Thus, 1739 (96.23\%) women were available for incidence analysis and $6.9 \%$ (120) of them became depressed by 2 weeks postpartum and achieved EPDS scores greater than 12 .

\section{Characteristics of the sample}

The mean age and age at marriage of mothers were $25.9 \pm 5.2$ years and $20.4 \pm 4$ years with a range of 16 to 45 and 9 to 42 years respectively. About half of mothers and their husbands' education was less than high school $(50.5 \%$ and $43.4 \%$ respectively), and their mean household income was $3,199,750 \pm 1.5$ Rials per month. The majority of mothers were homemakers (92.7\%), married (99.6\%), and had husbands who were employed in business (67.5\%), owned their own home (62\%), and lived in nuclear families (71.7\%).

Sixty-one percent of mothers did not have any children. For mothers having children at home, the age of the last child was between 12 and 267 months, and $42.7 \%$ were more than

Table I. Dependent and independent variables under study.

\begin{tabular}{|c|c|c|}
\hline Variables & Area & Maternal characteristics \\
\hline Dependent & Post-partum depression & Change in functioning, depressed mood or loss of interest and so on \\
\hline \multirow[t]{6}{*}{ Independent } & Socio-demographic & $\begin{array}{l}\text { Mother's age, marital age, marital status, parity, mothers and fathers' } \\
\text { education, mother and fathers' employment, total household income } \\
\text { and location of health centers }\end{array}$ \\
\hline & $\begin{array}{l}\text { Obstetric and } \\
\text { gynecological }\end{array}$ & $\begin{array}{l}\text { Medical problems, infertility, any complications during previous and } \\
\text { this pregnancy, sick leave during pregnancy, gestational age at the } \\
\text { first antenatal care visit, gestational age at each visit, gestational age } \\
\text { at the time of delivery, number of antenatal care visits, pregnancy } \\
\text { wantedness, participation in health education programs, weight gain, } \\
\text { mode of delivery, place of delivery, puerperium complications, breast } \\
\text { feeding status, birth weight, sex of the baby, and neonatal morbidity }\end{array}$ \\
\hline & Psychological & $\begin{array}{l}\text { Family history of depression and psychosis, history of psychosis, } \\
\text { previous post-partum depression, and pregnancy mood symptoms } \\
\text { (depression and anxiety) }\end{array}$ \\
\hline & Hormone related & $\begin{array}{l}\text { Irritable mood before menstruation, mood instability due to oral } \\
\text { contraceptive pills (OCP) and mood instability at puberty, and also } \\
\text { premenstrual syndrome that was assessed by PMSQ [12] }\end{array}$ \\
\hline & Psychosocial & $\begin{array}{l}\text { Social support or the lack of support, marital relationship, life events, } \\
\text { parental self-efficacy and abuse that including } 24 \text { questions related } \\
\text { to ever being abused or witnessing abuse before pregnancy, during } \\
\text { pregnancy and post-partum }\end{array}$ \\
\hline & Customs and rituals & $\begin{array}{l}\text { Forty-two days of rest after childbirth, people helping mother for free } \\
\text { with the care of other children, to give a party, to eat traditional food, } \\
\text { avoid visiting a person that has a heavy cold, avoid bad news because } \\
\text { this will affect the milk supply and so on }\end{array}$ \\
\hline
\end{tabular}


6 years old. $50.6 \%$ of mothers were recruited from rural PHCs.

A small proportion of mothers (12.2\%) in the study reported medical conditions. The most predominant of those was anemia, with $79.9 \%$ of cases. The majority of mothers (60.1\%) had a prenatal visit less than 9 times, the mean number of visits being $9.3(\mathrm{SD}=3.6)$. Approximately one third of mothers (34.5\%) entered labor naturally and about half of the babies (53.9\%) were born vaginally. $85.4 \%$ of babies were still breast-fed exclusively by mothers at three months post-partum. About half of the infants $(50.8 \%)$ were male. Eleven percent of infants experienced neonatal morbidity after birth, and premature birth represented the majority of those cases (57.88\%).

Approximately 42 (42/1739, 2.4\%) mothers reported having PPD prior to their recent pregnancy, 154 (154/1739, 8.8\%) mothers felt depression during first and second trimester of this pregnancy, and about half of mothers (43.3\%) had been feeling anxiety during pregnancy. Based on the General Health Questionnaire, approximately one third of mothers (37.8\%) were found to have health problems.

From the biological perspective, we used retrospective standardized questionnaires about irritable mood due to hormonal changes in a particular stage of a woman's life. Only a small number of mothers (14\%) reported having an irritable mood prior to menstruation. Nearly one sixth of mothers (14.7\%) who used oral contraceptive pills reported mood instability, and only $9 \%$ of them reported mood changes at puberty.

The mean scores of social support and social isolation based on the Social Support Appraisals scale (SSA) and Network Orientation Scale (NOS) were $47.24 \pm 4.91$ and $47.81 \pm 4.36$ with a minimum and maximum of 27, 69 and 22, 65 respectively. The mothers' mean score of relationship satisfaction based on the ENRICH Marital Inventory (MI) was $25.05 \pm 3.61$ with a minimum and maximum of 4 and 42 , and the mean score of mothers' self-efficacy about parenting was $7.96 \pm 1.49$ with a minimum and maximum of zero and 10.60 based on the Parental Expectation Survey (PES). The number of life events ranged from zero to 18 , with the mean being $2.81 \pm 2.73$, based on the Live Event Rating Scale (LERQ). Few mothers (12.21\%) in this study reported experiencing at least one kind of abuse. Neglect was the predominant (29\%) kind of abuse at all stages.

The number of cultural practices ranged from zero to 27 , with the mean being $14.13 \pm 3.9$.

\section{Univariate regression models}

Among the demographic variables, depression risk was associated with only one characteristic that was examined: husband's education. Mothers whose husbands were better educated had lower odds of raised EPDS scores (OR $=0.94(95 \% \mathrm{Cl}$ : 0.88-0.99)).

We inspected whether a history of medical problems with focus on obstetrics and gynecology data increased risk of PPD. Increased odds of PPD were linked with two pregnancy-related variables: recurrent urinary infection $(\mathrm{OR}=1.7$ (95\% Cl: 1.02-2.82)), and unplanned pregnancy $(\mathrm{OR}=1.55(95 \% \mathrm{Cl}: 1.01-2.36))$. Concerning postbirth variables only women who experienced puerperal complications were at a significantly elevated risk of developing PPD.

Mothers who reported depression and anxiety during pregnancy were nearly two times more likely to develop depression than mothers who did not report these $(\mathrm{OR}=2.26(95 \% \mathrm{Cl}: 1.38-3.7)$ and $\mathrm{OR}=1.82(95 \% \mathrm{Cl}: 1.25-2.64)$ respectively) Moreover, mothers with high scores in the General Health Questionnaire (GHQ) during pregnancy were two times more likely to be prone to show PPD than mothers with scores lower than the threshold $(\mathrm{OR}=2.16(95 \% \mathrm{Cl}: 1.48-3.13))$ [21].

Most psychosocial variables significantly contributed to PPD. The results of univariate analysis showed an increased risk of PPD for mothers with less social support $(\geq 51)(\mathrm{OR}=1.04(95 \% \mathrm{Cl}$ : $1.01-$ 1.08)) compared with women who had a greater amount of support $(\leq 44)$ based on scores of the Social Support Scale. Increase in marital relationship satisfaction (scored $\geq 27$ based on the ENRICH Marital Inventory) and sufficiency in parenting (scored $\geq 9$ based on Parental Self-Efficacy) were significant predictors of screening positively with the EPDS and decreased risk of PPD (OR $=0.94(95 \% \mathrm{Cl}$ : 0.89$0.98)$ and $\mathrm{OR}=0.79(95 \% \mathrm{Cl}: 0.7-0.88)$ respectively) compared to mothers with low marital satisfaction and insufficient parenting skills. Women with PPD also had a significantly higher number of stressful events compared to non-depressed mothers $(O R=$ 1.08 (95\% Cl: 1.02-1.14)).

Women who perform more cultural practices and rituals were at significantly decreased risk for PPD (OR $=0.94(95 \% \mathrm{Cl}: 0.9-0.99))$ relative to mothers who perform these practices less.

Table II shows the frequency and percentage for PPD by each category of the significant variables, univariate odds ratio with $95 \%$ confidence interval, $p$-values, and B coefficient, based on EPDS scores.

\section{Multivariate logistic regression model}

There were 1539 postnatal EPDS scores and 12 available for multiple logistic regression analysis. Applying the $\chi^{2}$ statistic derived from the log-likelihood, the goodness-of-fit for the model was evaluated. Variables utilized for the model consisting of demographic, obstetric and gynecological 
Table II. Risk factors of post-partum depression at two weeks post-partum in women attending Mazandaran province Primary Health Centers using simple logistic regression, $2009(n=1739)$

\begin{tabular}{|c|c|c|c|c|}
\hline Risk factors & $\begin{array}{l}\text { Non-depressed } \\
\text { EPDS } \leq 12\end{array}$ & $\begin{array}{l}\text { Depressed } \\
\text { EPDS }>12\end{array}$ & $\begin{array}{l}\text { Unadjusted odds ratio } \\
\qquad(95 \% \mathrm{Cl})\end{array}$ & Value of $p$ \\
\hline Husband education & 1619 & 120 & $0.94(0.88-0.99)$ & 0.03 \\
\hline Recurrent urinary infection: & & & $1.7(1.02-2.82)$ & \\
\hline Yes & 170 & 20 & & 0.03 \\
\hline No & 1449 & 100 & & \\
\hline Planned pregnancy: & & & $1.55(1.01-2.36)$ & \\
\hline No & 310 & 32 & & 0.04 \\
\hline Yes & 1306 & 87 & & \\
\hline Puerperal complications: & & & $1.77(1.2-2.62)$ & \\
\hline Yes & 395 & 44 & & 0.004 \\
\hline No & 1196 & 75 & & \\
\hline Depression in $1^{\text {st }}$ or $2^{\text {nd }}$ trimester of pregna & ncy: & & $2.26(1.38-3.7)$ & \\
\hline Yes & 146 & 22 & & 0.001 \\
\hline No & 1473 & 98 & & \\
\hline Anxiety in pregnancy: & & & $1.82(1.25-2.64)$ & \\
\hline Yes & 677 & 68 & & 0.002 \\
\hline No & 942 & 52 & & \\
\hline General health status from GHQ: & 1618 & 120 & & \\
\hline Not healthy $(>21)$ & 585 & 66 & $1.06(1.03-1.08)$ & 0.01 \\
\hline Healthy $(\leq 21)$ & 1034 & 54 & $2.16(1.48-3.13)$ & 0.01 \\
\hline Social support during pregnancy from SSA: & 1618 & 120 & & \\
\hline High $(\geq 51)$ & 355 & 38 & $1.04(1.01-1.08)$ & 0.01 \\
\hline Medium (46-50) & 802 & 54 & $1.76(1.06-2.92)$ & 0.02 \\
\hline Low $(\leq 45)$ & 461 & 28 & $1.1(0.69-1.77)$ & 0.66 \\
\hline $\begin{array}{l}\text { Marital satisfaction during pregnancy } \\
\text { from } \mathrm{Ml} \text { : }\end{array}$ & 1618 & 120 & & \\
\hline Low $(\leq 23)$ & 361 & 41 & $0.94(0.89-0.98)$ & 0.01 \\
\hline Medium (24-26) & 739 & 40 & $1.5(0.95-2.36)$ & 0.07 \\
\hline High $(\geq 27)$ & 518 & 39 & $0.71(0.45-1.13)$ & 0.15 \\
\hline Number of life events from LERS: & 1619 & 120 & & \\
\hline$\geq 4$ & 509 & 43 & $1.08(1.02-1.14)$ & 0.007 \\
\hline $2-3$ & 486 & 33 & $1.19(0.77-1.85)$ & 0.44 \\
\hline$\leq 1$ & 624 & 44 & $0.96(0.6-1.53)$ & 0.87 \\
\hline Postnatal parenting self-efficacy from PES: & 1446 & 112 & & \\
\hline $\operatorname{Low}(\leq 7)$ & 422 & 20 & $0.79(0.7-0.88)$ & 0.01 \\
\hline Medium (7.01-8.91) & 700 & 49 & $2.8(1.61-4.85)$ & 0.01 \\
\hline High ( $\geq 9)$ & 324 & 43 & $1.47(0.86-2.51)$ & 0.15 \\
\hline Cultural practices & 1434 & 110 & $0.94(0.9-0.99)$ & 0.04 \\
\hline
\end{tabular}


Table III. Mental health, psychosocial, cultural and demographic factors and risk of PPD at 2 weeks post-partum in women attending Mazandaran province Primary Health Centers, 2009, using backward multiple logistic regression $(n=1539)$

\begin{tabular}{|lccccc|}
\hline Risk factors & $B$ & $B(\mathrm{SE})$ & Odds ratio & $95 \% \mathrm{Cl}$ & Value of $p$ \\
\hline General health status from GHQ & 0.06 & 0.01 & 1.06 & $1.04-1.09$ & 0.001 \\
\hline Postnatal parenting self-efficacy from PES & -0.24 & 0.06 & 0.78 & $0.69-0.88$ & 0.001 \\
\hline Marital satisfaction from MS & -0.05 & 0.02 & 0.94 & $0.9-0.99$ & 0.03 \\
\hline Number of ritual practices & -0.05 & 0.02 & 0.94 & $0.89-0.99$ & 0.004 \\
\hline Husband education & -0.06 & 0.03 & 0.93 & $0.88-0.99$ & 0.04 \\
\hline
\end{tabular}

GHQ - General Health Questionnaire, PES - Parental Expectation Survey, MS - ENRICH Marital Satisfaction.

factors, mental health, social factors and finally number of cultural and ritual practices were all associated with greater odds of PPD. The backward elimination process produced a model with variables including general health status in pregnancy based on GHQ scores, sufficient parenting based on PES, marital satisfaction based on MI, husbands' education, and number of ritual practices. The regression model showed that there was increased risk of PPD with lower state of general health $(\mathrm{OR}=1.06(95 \% \mathrm{Cl}: 1.04-1.09))$. The risk of PPD decreased with sufficient parenting skills $(\mathrm{OR}=0.78$ (95\% Cl: 0.69-0.88)), increased marital satisfaction $(\mathrm{OR}=0.94(95 \% \mathrm{Cl}$ : 0.9-0.99)), higher number of ritual practices $(\mathrm{OR}=0.94(95 \% \mathrm{Cl}$ : 0.89-0.99)) and husband with better education $(\mathrm{OR}=0.03$ (95\% Cl: 0.88-0.99)). Table III shows $\mathrm{B}$ coefficient estimates and the corresponding adjusted odds ratios indicating the independent effect of each significant variable controlling for the effect of other variables in the model.

The model for the above regression is: Log odds (elevated postnatal EPDS) $=0.52+0.06(\mathrm{GHQ})-$ 0.24 (parental self-efficacy) -0.05 (marital satisfaction) -0.05 (cultural practices) -0.06 (husband education).

\section{Discussion}

The incidence of PPD (6.9\%) was not uncommon in the Iranian population. Although the prevalence rate and associated factors of PPD have been more frequently reported, the incidence of this disorder has been less studied. In this prospective study the incidence rate and associated predictors of PPD were investigated as close as possible to 2 weeks postpartum for the first time in Iran.

The comparison of PPD incidence is not easy because the timing of assessment is varied and it is uncertain that all cases occur after birth [21]. Consistent with the study by Chaudron et al. [21], who reported $5.8 \%$ incidence of PPD among American women during 1 to 4 weeks after birth, this study showed a cumulative incidence of PPD at 2 weeks postpartum of $6.9 \%$. However, it is lower than the $10 \%$ and $11 \%$ incidence rate found in Groer and Morgan's [22] study during 4-6 weeks postpartum among Australian mothers and the study by Chandran et al. [23] in rural areas of India at 6-16 weeks postpartum. The differences in reported PPD rate are influenced by many factors such as samples and sampling methods, people who applied them, differences in symptom definition and expression and the time after childbirth when the depression is evaluated $[24,25]$. This makes comparison between studies difficult.

Interestingly, most of the risk factors for PPD identified in previous surveys also were significant in this study. In both univariate and multivariate analysis, socio-demographics, obstetrics and gynecology, mental health and psychosocial factors were significant predictors of PPD.

The strongest predictor of PPD in this study was psychiatric distress according to the GHQ. Other studies have also shown that mothers with PPD were most likely to have psychiatric symptoms during pregnancy $[4,11,26-36]$. The study by Nielsen et al. [37] also found a significant increase in depressive symptoms at the fourth month post-partum among Danish women who reported higher scores of GHQ during late pregnancy.

A combination of three meta-analyses concluded that anxiety during pregnancy is one of the strongest risk factors for developing PPD [10]. Matthey et al. [38] stated that anxiety may be a more significant predictor for PPD than the history of depression. Recent studies concluded that anxiety during pregnancy should be focused on in order to alert health care workers because it is a key risk factor for PPD [4, 32, 33, 38-40].

While depression during the first and second trimester of pregnancy was a significant risk factor for PPD in the single regression model, surprisingly it did not turn out to be significant in the final model. A statistical reason could be a possible explanation for this lack of association; when a number of variables were used, other variables contributed significantly to the variation in PPD as predictors of PPD [41]. 
Several studies have demonstrated that psychosocial factors make women vulnerable to PPD $[2,3,10,42]$. The findings of our study are consistent with other studies on the contribution of baby-related stressors to PPD [43]. Our results are also consistent with those of Astbury et al. [44] and Milgrom et al. [32], who found low maternal confidence in infant care to be a significant risk factor for PPD in Australian women.

The other most dominant PPD risk factor that is frequently studied is marital dissatisfaction [2, $26,33,36,41,45,46]$. Our study also confirmed the importance of the marital relationship in risk of developing PPD, similar to the results of a study by Huang and Mathers [24] in Taiwan, and Fisher et al. [47] in Vietnamese women. A review study by Klainin and Arthur [3] in Asian countries showed that mothers in UAE, Hong Kong, Turkey and India who have marital conflicts are at risk of PPD. A poor marital relationship, such as inability to confide in a partner, may contribute to depression after giving birth [48].

While some medical and obstetric factors such as recurrent urinary infection, unplanned pregnancy and puerperal complications were clearly important and significantly associated with depressive symptomatology individually, these variables did not remain significant when they were included in the model. Several studies reported an association between obstetrics and gynecological factors $[11,49,50]$, but similar to our study others did not confirm this result $[37,51,52]$. Thus the existing evidence is as yet inconsistent.

It is uncertain whether socio-demographic factors predispose women to PPD [50]. The relatively weak contribution of most socio-demographic factors in this study is comparable to other research findings [10, 53]. Only lower husband's education was significantly associated with depressive symptoms and retained in the predictive model as in Klainin and Arthur's [3] report. As for husbands' demographic characteristics, a Pakistani study by Rahman et al. [28] yielded a significant positive association between uneducated husbands and persistent PPD for 1 year after birth. A review of 42 studies in Asian countries conducted by Klainin and Arthur [3] revealed that the following socio-demographic factors were potential risk factors for PPD: economic problems, being hungry in the past month, homemaker, immigrant, having an unemployed or uneducated husband, polygamy and displeasure with living situation.

Unsurprisingly, the results of this study in a traditional society showed the influence of cultural practices on preventing PPD to be significant. Wong and Fisher (2009) assessed the role of confinement, which should mean receiving social support from the family, mandated rest, receiving gifts, gaining a respectable new social position, increase in mothers' self-esteem and removing her from any isolation which could result in decreased depression in a Chinese society. Dankner et al. [54] stated that in some traditional cultural settings, due to the traditional practices that encourage maternal role transition, the physical and psychological pain of mothers is decreased. The PPD may occur as a result of the absence of rituals in several ways, such as decreasing the mothers' self-confidence, being unsure regarding access to social support, increasing the probability of physical activities leading to fatigue, and experiencing stress in terms of the relationships with significant others. Moreover, the absence of ritual practices indicates the uncertainty of society concerning the mothering status, an ambivalence which aggravates her role conflict, and affects her self-esteem [24, 55].

To our knowledge, this population-based longitudinal study is the first to evaluate PPD risk factors using both univariate and multivariate analysis while controlling for the symptoms of depression in pregnancy in Iran. The results support early detection of mothers at risk for PPD in pregnancy and after birth, based on depressive symptoms in the immediate postpartum period and should take into consideration the mental health, psychosocial, socio-demographic and cultural risk factors. Previous studies have also reported that psychological problems during pregnancy could be a "red flag" for increased risk of PPD. Thus, while our study excluded depressed mothers in the third semester of pregnancy, health care providers must keep in mind that women may present with depression during pregnancy. As pregnant women have frequent contact with health care providers, a pregnancy and postpartum appointment is an opportunity to screen mothers for PPD [56].

The EPDS is a screening tool at best. Subjects with high scores $(>12)$ on this scale were labeled as probable PPD in this study. Although most research indicates high sensitivity and specificity of the EPDS, it would have been ideal to have been able to confirm mothers with increased EPDS scores with a structured clinical interview. However, given the large sample size and cultural barrier, it was not easy to perform a diagnostic interview to confirm PPD. Another limitation of this study was that although the researchers made their best effort to measure the risk factors prior to onset of depression, a few factors could only be assessed at three months postpartum (such as cultural factors and mother's self-efficacy). However, these factors are not expected to vary very much within a short period.

In conclusion, as depression is associated with significant consequences such as chronicity and 
suicide [57] thus, further investigation needs to be conducted on the global scale for prevalence and incidence of childbearing women's experiences with depressive symptoms and related risk factors, especially in a diverse population.

\section{Acknowledgments}

We are grateful to Mazandaran University of Medical Sciences in Iran and University Putra Malaysia for supporting this project. The authors would like to thank the health care providers for their assistance during data collection and all mothers who attended PHCs for participating in the study.

\section{Conflict of interest}

The authors declare no conflict of interest.

\section{References}

1. American Psychiatric A. Quick reference to the diagnostic criteria from DSM-IV-TR. Amer Psychiatric Pub Incorporated 2000.

2. Beck CT. Predictors of postpartum depression: an update. Nurs Res 2001; 50: 275-85.

3. Klainin P, Arthur DG. Postpartum depression in Asian cultures: a literature review. Int J Nurs Stud 2009; 46: 1355-73.

4. Azimi-Lolaty H, Danesh M, Hosaini SH, Khalilian A, Zarghami M. Prevalence and predictors of postpartum depression among pregnant women referred to mother-child health care clinics (MCH). Res J Biol Sci 2007; 2: 285-90.

5. Ghafarinezhad A, Joybari F, Poya F. Prevalence of postpartum depression in Kerman. J Think Behav 2000; 5 : 24-9.

6. Zahraei H, Khodadost R, Asadollahi M, Nasrollah B, Ghorban A. Risk factors of postpartum depression in Isfehan. J Isfihan Nurs Midwif School 1998; 11: 57-65.

7. Namazi S. Risk factors of postpartum depression, hormozggan. J Med Hormozggan 2000; 3: 17-24.

8. Lusskin SI, Pundiak TM, Habib SM. Perinatal depression: hiding in plain sight. Can J Psych 2007; 52: 479-88.

9. Josefsson A, Sydsjö G. A follow-up study of postpartum depressed women: recurrent maternal depressive symptoms and child behavior after four years. Arch Women's Mental Health 2007; 10: 141-5.

10. Robertson E, Grace S, Wallington T, Stewart DE. Antenatal risk factors for postpartum depression: a synthesis of recent literature. Gen Hosp Psych 2004; 26: 289-95.

11. Bloch M, Rotenberg N, Koren D, Klein E. Risk factors for early postpartum depressive symptoms. Gen Hosp Psych 2006; 28: 3-8.

12. Mortola JF, Girton L, Beck L, Yen SSC. Diagnosis of premenstrual syndrome by a simple, prospective, and reliable instrument: the calendar of premenstrual experiences. Obstet Gynecol 1990; 76: 302-7.

13. Vaux A, Phillips J, Holly L, Thomson B, Williams D, Stewart D. The social support appraisals (SS-A) scale: studies of reliability and validity. Am J Commun Psychol 1986; 14: 195-218.

14. Vaux A. Factor structure of the Network Orientation Scale. Psychol Rep 1985; 57: 1181-2.
15. Goldberg D. The detection of psychiatric illness by questionnaire. Oxford University Press, London 1972.

16. Olson DH, Fournier DG, Druckman JM, et al. ENRICH: Enriching and nurturing relationship issues, communication and happiness. Family inventories. Family social sciences. University of Minnesota, St. Paul, Minnesota. 1985.

17. Holmes TH, Rahe RH. The social readjustment rating scale. J Psychosom Res 1967; 11: 213-8.

18. Reece SMC. The parent expectations survey. Clin Nurs Res 1992; 1: 336-46.

19. Cox JL, Holden JM, Sagovsky R. Detection of postnatal depression. Development of the 10-item Edinburgh Postnatal Depression Scale. Br J Psych 1987; 150: 782-6.

20. Rychnovsky JD, Brady MA. Choosing a postpartum depression screening instrument for your pediatric practice. J Pediatr Health Care 2008; 22: 64-7.

21. Chaudron LH, Klein MH, Remington P, Palta M, Allen C, Essex MJ. Predictors, prodromes and incidence of postpartum depression. J Psychosom Obstet Gynecol 2001; 22: 103-12.

22. Groer MW, Morgan K. Immune, health and endocrine characteristics of depressed postpartum mothers. Psychoneuroendocrinology 2007; 32: 133-9.

23. Chandran M, Tharyan P, Muliyil J, Abraham S. Post-partum depression in a cohort of women from a rural area of Tamil Nadu, India: Incidence and risk factors. $\mathrm{Br}$ J Psych 2002; 181: 499-504.

24. Huang YC, Mathers N. Postnatal depression - biological or cultural? A comparative study of postnatal women in the UK and Taiwan. J Adv Nurs 2001; 33: 279-87.

25. Halbreich U, Karkun S. Cross-cultural and social diversity of prevalence of postpartum depression and depressive symptoms. J Affect Disord 2006; 91: 97-111.

26. Righetti-Veltema M, Conne-Perréard E, Bousquet A, Manzano J. Risk factors and predictive signs of postpartum depression. J Affect Disord 1998; 49: 167-80.

27. Patel V, Rodrigues M, DeSouza N. Gender, poverty, and postnatal depression: a study of mothers in Goa, India. Am J Psychiatry 2002; 159: 43-7.

28. Rahman A, Iqbal Z, Waheed W, Hussain N. Translation and cultural adaptation of health questionnaires. J Pak Med Assoc 2003; 53: 142-6.

29. Henshaw C. Mood disturbance in the early puerperium: a review. Arch Women's Mental Health 2003; 6: 33-42.

30. Husain N, Bevc I, Husain M, Chaudhry IB, Atif N, Rahman A. Prevalence and social correlates of postnatal depression in a low income country. Arch Women's Mental Health 2006; 9: 197-202.

31. Watanabe M, Wada K, Sakata Y, et al. Maternity blues as predictor of postpartum depression: a prospective cohort study among Japanese women. J Psychosom Obstet Gynecol 2008; 29: 211-7.

32. Milgrom J, Gemmill AW, Bilszta JL, et al. Antenatal risk factors for postnatal depression: a large prospective study. J Affect Disord 2008; 108: 147-57.

33. Kirpinar I, Gözüm S, Pasinlioğlu T. Prospective study of postpartum depression in eastern Turkey prevalence, socio-demographic and obstetric correlates prenatal anxiety and early awareness. J Clin Nurs 2009; 19: 422-31.

34. Mohammad KI, Gamble J, Creedy DK. Prevalence and factors associated with the development of antenatal and postnatal depression among Jordanian women. Midwifery 2011; 27: e238-45.

35. Goyal D, Gay C, Lee KA. How much does low socioeconomic status increase the risk of prenatal and postpartum depressive symptoms in first-time mothers? Women's Health Issues 2010; 20: 96-104. 
36. Nagy E, Molnar P, Pal A, Orvos H. Prevalence rates and socioeconomic characteristics of post-partum depression in Hungary. Psych Res 2011; 185: 113-20.

37. Nielsen D, Videbech P, Hedegaard M, Dalby J, Secher NJ. Postpartum depression: identification of women at risk. BJOG 2000; 107: 1210-7.

38. Matthey S, Barnett B, Howie P, Kavanagh DJ. Diagnosing postpartum depression in mothers and fathers: whatever happened to anxiety? J Affect Disord 2003; 74: 139-47.

39. Grussu P, Quatraro RM. Prevalence and risk factors for a high level of postnatal depression symptomatology in Italian women: a sample drawn from ante-natal classes. Eur Psych 2009; 24: 327-33.

40. Rambelli C, Montagnani MS, Oppo A, et al. Panic disorder as a risk factor for post-partum depression: results from the Perinatal Depression-Research and Screening Unit (PND-ReScU) study. J Affect Disord 2010; 122: 139-43.

41. Escribà-Agüir V, Artazcoz L. Gender differences in postpartum depression: a longitudinal cohort study. J Epidemiol Com Health 2010; 65: 320-6.

42. Logsdon MC, Usui W. Psychosocial predictors of postpartum depression in diverse groups of women. West J Nurs Res 2001; 23: 563-74.

43. Records K, Rice M. Lifetime physical and sexual abuse and the risk for depression symptoms in the first 8 months after birth. J Psychosom Obstetr Gynecol 2009; 30: 181-90.

44. Astbury J, Brown S, Lumley J, Small R. Birth events, birth experiences and social differences in postnatal depres sion. Aus J Public Health 1994; 181: 76-184.

45. O'Hara MW. Interpersonal psychotherapy for postpartum depression. Women's Health Issues 1995; 5: 75-6.

46. Sawyer A, Ayers S, Smith H. Pre- and postnatal psychological wellbeing in Africa: a systematic review. J Affect Disord 2010; 123: 17-29.

47. Fisher JR, Morrow MM, Ngoc NT, Anh LT. Prevalence, nature, severity and correlates of postpartum depressive symptoms in Vietnam. BJOG 2004; 111: 1353-60.

48. Lee DTS, Yip ASK, Leung T, Chung TKH. Ethnoepidemiology of postnatal depression: prospective multivariate study of sociocultural risk factors in a Chinese population in Hong Kong. Br J Psych 2004; 184: 34-40.

49. Josefsson A, Angelsiöö L, Berg G, et al. Obstetric, somatic, and demographic risk factors for postpartum depressive symptoms. Obstet Gynecol 2002; 99: 223-8.

50. Sierra J. Risk factors related to postpartum depression in low-income Latina mothers. Dissertation for master of sciences. University of Connecticut 2008.

51. Patel RR, Murphy DJ, Peters TJ. Operative delivery and postnatal depression: a cohort study. Br Med J 2005; 330: 879.

52. Saisto T, Salmela-Aro K, Nurmi JE, Halmesmäki E. Psychosocial predictors of disappointment with delivery and puerperal depression. Acta Obstet Gynecol Scand 2001; 80: 39-45.

53. Boyce PM. Risk factors for postnatal depression: a review and risk factors in Australian populations. Arch Women's Mental Health 2003; 6: 43-50.

54. Dankner R, Goldberg RP, Fisch RZ, Crum RM. Cultural elements of postpartum depression: a study of 327 Jewish Jerusalem women. J Reprod Med 2000; 45: 97-104.

55. Hung $\mathrm{CH}$, Chung $\mathrm{HH}$ The effects of postpartum stress and social support on postpartum women's health status. J Adv Nurs 2001; 36: 676-84

56. Choi SK, Kim JJ, Park YG, Ko HS, Park IY, Shin JC. The Simplified Edinburgh Postnatal Depression Scale (EPDS) for antenatal depression: is it a valid measure for pre-screening? Int J Med Sci 2012; 9: 40-6.
57. Mojs EH, Warchoł-Biedermann K, Głowacka MD, Strzelecki W, Ziemska B, Samborski W. Are students prone to depression and suicidal thoughts? Arch Med Sci 2015; 11: 605-11. 